\title{
Result of a British Survey on Artificial Cardiac Pacemakers
}

\author{
EDGAR SOWTON,* M.A., M.D., M.R.C.P.
}

Brit. med. F., 1968, 2, 11-13

The use of cardiac pacemakers in the treatment of patients with complete heart block has increased greatly over the past two years in the United States, France, Germany, and Scandinavia and to a less extent also in the British Isles. In order to obtain some basic data concerning the clinical situation and performance of pacemakers in Britain a survey was carried out in cooperation between the Institute of Cardiology, the Ministry of Health, and the agents for all types of pacemakers available. The survey was retrospective and covered every pacemaker sold in Britain between 1 April 1965 and 31 March 1966 inclusive.

The type of pacemaker, serial number, date of dispatch, and bospital to which the pacemaker was sent were supplied by the manufacturers or agent for every pacemaker sold within these dates and a questionary (see below) was sent to determine the fate of the unit. The information represents the position in December 1966.

\section{Results}

During the 12 months 540 long-term cardiac pacemakers were sold within the British Isles, of which 421 were totally implantable. This survey deals only with these fully implantable units, and questionaries relating to 341 ( $81 \%$ ) were returned. Pacemakers manufactured by Devices Ltd., ElemaSchönander AB, Pye Ltd., and Medtronic Inc. were represented, but since the actual sales figures might have commercial value they cannot be given in detail. No Cordis, Vitatron, Electrodyne, or General Electric pacemakers were sold during this period.

Of the 341 questionaries returned $32(9.4 \%)$ indicated that the pacemaker could not be traced by the hospital which had paid for it. Since some of these pacemakers were presumably implanted in patients it seems very unlikely that satisfactory arrangements were made for their replacement at the end of their useful life. This lack of follow-up information on approximately one in every 10 pacemakers delivered to hospitals may represent a significant danger to patients.

A further 31 pacemakers were traced, but had not been implanted into patients. Many of these had been used for

* Institute of Cardiology, London W.1.

Address for reprints : 35 Wimpole Street, London W.1.

\section{PACEMAKER INVESTIGATION}

Minestry of Health/Institute of Cardiology

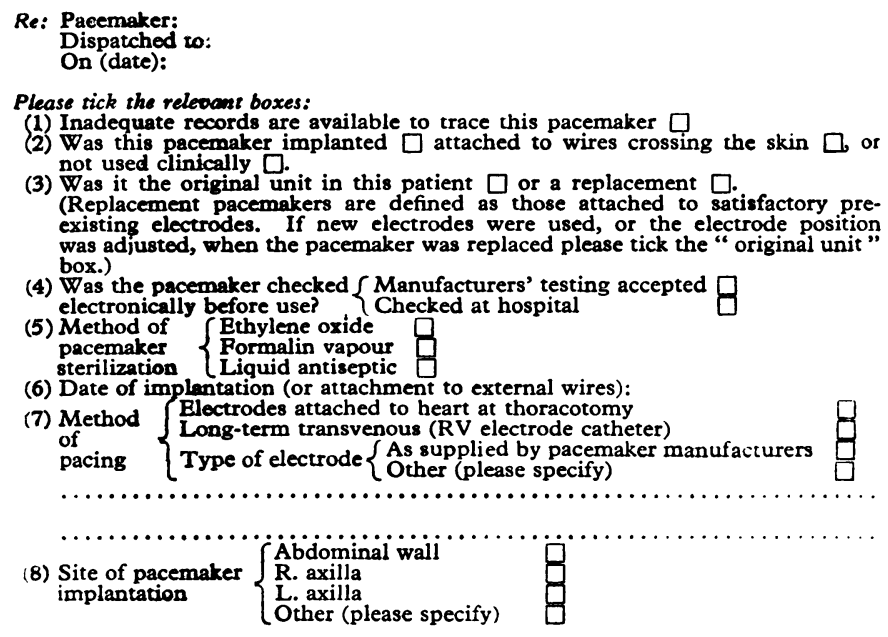

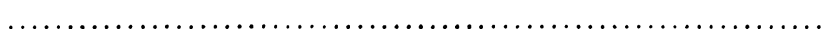

(9) Pacing continuing satisfactorily ${ }_{\text {. }}$ If not, please give date of failure of pacing (including elective replacement of unit):

10) Cause of $\begin{aligned} & \text { Cailure } \\ & \text { of pacing }\end{aligned}\left\{\begin{array}{l}\text { Pacemaker fault } \\ \text { Electrode fault } \\ \text { Infection } \\ \begin{array}{l}\text { Elective replacement of unit } \\ \text { (please specify reason) } \\ \text { Other (please specify) }\end{array}\end{array}\right.$

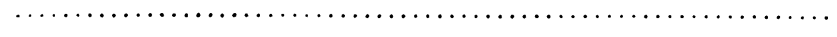

11) Type of $\begin{gathered}\text { pacemaker } \\ \text { failure }\end{gathered}\left\{\begin{array}{l}\text { Rapid rate of }\left\{\begin{array}{l}\text { Pacemaker } \\ \text { Heart }\end{array}\right. \\ \text { Slow rate of }\left\{\begin{array}{l}\text { Pacemaker } \\ \text { Heart }\end{array}\right. \\ \text { Other (please specify) }\end{array}\right.$

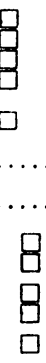

(12) Had pacing stopped before the pacemaker was replaced? Yes $\square$ No $\square$

(13) After removal

was the

$\left\{\begin{array}{l}\text { Not examined } \\ \text { Returned to manufacturer } \\ \text { Examined elsewhere } \\ \text { (please give further details if possible) }\end{array}\right.$

Information Rblating to DaAth DURING TRBatmbnt with this

(14) Was stable pacing present until death? Yes $\square \quad$ No $\square \quad$ Not known $\square$

If No, please give further details if possible:

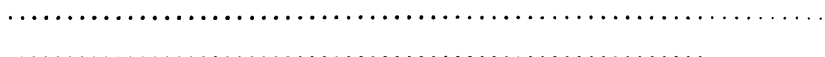

(15) Was there any evidence of return of $\mathrm{A}-\mathrm{V}$ conduction, even temporarily, before death? Yes $\square$ No $\square$

(16) Before death, did the heart fail to respond to apparently normal pacing stimuli? Yes $\square$ No $\square$ Not known $\square$

(17) Was death related to failure of pacemaker or electrode? \begin{tabular}{ll} 
Pacemaker: Yes & No \\
Electrode: & Yes $\square$ Not known $\square$ \\
\hline
\end{tabular}

(18) After death was the pacsmaker/electrode system apparen.ly nu:mat If No, please give further details if possible.

(19) Was the pacemaker removed after death? Yes $\square$. No $\square$

If so, was it $\left\{\begin{array}{l}\text { Returned for manufacturers' testing? } \\ \text { Examined at hospital (please give details)? }\end{array}\right.$

Surgeon's or Physician's comments:

(1) Are you able to identify any other significant features in the failure of this pacemaker/electrode system?

(2) Which features, if any, should be improved in this pacemaker? 
some time externally, but $15(4,4 \%)$ had not been used clinically at all.

The average delay between dispatch of a pacemaker from the agent and its implantation into a patient was 24 days, though some pacemakers were not used until more than 120 days after dispatch. A delay of about three weeks seems satisfactory, but a pacemaker which has already had a shelf life of four months in the hospital, in addition to the period between leaving the factory and being supplied from the agent, is unlikely to perform completely normally after implantation in a patient.

Failure of pacing was often not due to failure of the pacemaker itself. There were 203 returns indicating pacing failure, of which $87(43 \%)$ were attributed to causes other than generator failure: an analysis of the other causes is shown in the Table. Cessation of pacing was attributed to death of the patient in almost $15 \%$ of cases, but deaths due to generator failure are not included in the Table. Eight deaths were attributed to pacemaker failure, and these have been included in the statistics for "generator failure."

\section{Analysis of Causes for Failure of Pacing in 203 Cases with Completely Implanted Units

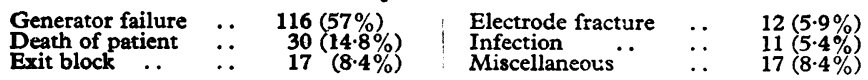

Infection around the pacemaker resulted in pacing failure in 11 cases, but the average time of satisfactory pacing before this event was 30 weeks. Pacing failure due to infection was therefore a relatively late complication. Only scanty information is available concerning the methods of sterilization, but infection occurred with pacemakers sterilized in ethylene oxide, in formalin vapour, and in liquid antiseptic. The infection rate was not significantly different between different manufacturers' pacemakers.

A high threshold causing pacing failure ("exit block") occurred in 17 patients. This represents $20 \%$ of the 87 cases where pacing failed though the pacemaker itself continued to function normally. The condition was noted almost exclusively with endocardial systems, and on average was preceded by just over four weeks' satisfactory pacing. 'This high incidence may reflect difficulty in positioning the endocardial electrodes satisfactorily within the right ventricle.

Electrode fracture affected only the U.S.C.I. C50 electrode catheter, which was designed for short-term use and is now no longer employed for long-term pacing. The average time of pacing before fracture was 24 weeks.

Thirty-five patients died during the period covered by this survey. Since this report is primarily a follow-up of pacemakers and not of patients the figures can be only approximate, but this represents about one in eight of the treated patients. Deaths were not related to the type of pacemaker, and inadequate information is available to relate deaths to competition between paced and sinus rhythms. In five patients pacing was known to have stopped before death, and in eight patients death was attributed to a pacemaker fault. These eight deaths represent $3 \%$ of the total patients treated, or $23 \%$ of the patients who died.

Failure of pacing from such causes as malplacement of the clectrode, broken connexions, poor screw contacts, etc., totalled 17 instances, and these are shown in the Table as the miscellaneous group.

In 63 instances pacing had stopped before the pacemaker was replaced, and this represents about one in three of the patients in whom pacing failed from any cause during the period of this survey. This figure is surprisingly high, and again indicates poor follow-up arrangements.

Pacemaker failure itself occurred in 116 cases, representing $41 \%$ of the total number implanted during the 12 -month period. Most types of pacemakers were affected but the figures give no indication of the final lifetime of each type of pacemaker, since the actual date of failure of every pacemaker included in the survey would be needed for this to be calculated. Many of the pacemakers covered by the present report are still functioning in patients.

Of the 116 pacemakers which failed during this survey 31 $(27 \%)$ did so with an increasing rate, and this mode of failure affected Devices, Medtronic, and Pye pacemakers. A rapid rate is less satisfactory than slowing, which allows the patient's idioventricular rhythm to take over from a failing pacemaker.

\section{Discussion}

The information on which these figures are based suffers from several deficiencies. It cannot be assumed that surgeons, physicians, or technicians who actually filled in the questionaries all had similar views on what constituted pacemaker failure as opposed to pacing failure due, for example, to a faulty connexion. Though the questionary was designed to eliminate this problem so far as possible, some errors must be accepted. Also, there must be some doubt regarding the accuracy of statements made concerning such situations as exit block or death related to faulty pacemakers, since supporting evidence is not available. Despite these limitations the survey has provided a considerable amount of clinically useful information.

It is apparent that there are large areas where improvements in patient-care can be made, particularly in follow-up arrangements for paced patients. Since the life of a patient may depend on an implanted pacemaker, and every such pacemaker must eventually fail, it seems desirable for accurate records to be kept, for the patient to be seen regularly, and for pacemakers to be replaced near the end of their useful lives but before they actually fail. This should now be achieved in a high proportion of paced patients, but had not occurred in over one-third of the patients in this survey.

The high incidence of pacing failure from causes apart from generator malfunction also seems unacceptable. A possible explanation is the lack of experience at many hospitals in the careful technique needed for satisfactory pacemaker installation, while another may be a lack of specialized equipment for checking pacemakers and myocardial thresholds during implantation.

The true lifetimes of the various types of pacemakers cannot be determined from this survey, but the minimum figures available indicate that most units covered are equally satisfactory during the first year of pacing. The disappointingly short lifetime of the Devices Axillary pacemaker at the time led to alterations in design and construction, so that the current model is claimed to have a lifetime equivalent to the same manufacturers' Abdominal type. The Medtronic pacemakers covered in this survey are of the same design as the versions now available, and the average lifetime is claimed to be well in excess of the minimum determined here ; elective replacement of this model after two and a half years of pacing has been recommended by the manufacturers (Medtronic Reliability Report, 1966).

A review of paced patients covering the period of the present survey has been published by Parsonnet, Gilbert, and Zucker (1966), who deal with 93 patients treated with Electrodyne and Cordis units. They state that after the first few weeks have been successfully negotiated there is a high chance that uninterrupted pacing will continue for one to two years, until battery exhaustion necessitates replacement of the pacemaker. A similar cornment could be made only for about half the patients dealt with in this survey.

From figures quoted at the 1967 meeting of the Scandinavian Society of Cardiology it appears that there are approximately twice as many patients with pacemakers in Sweden as in Britain, despite the fact that the population is only one-seventh of that of the United Kingdom. Since it has been shown that medical treatment of heart block results in a one-year mortality of $40 \%$ 
(Johansson, 1966) while paced patients have a one-year mortality of only 10-15\% (Chardack, 1967 ; Sowton, 1967) it seems likely that the number of paced patients in Britain will continue to increase rapidly. It is to be hoped that improvements in pacemaker design and manufacture will continue, and will be matched by an increasing standard of implantation and followup care.

\section{Summary and Conclusions}

A retrospective survey of all cardiac pacemakers sold over a 12-month period in Britain was carried out and an $81 \%$ return achieved.

Of the pacing systems which failed the cause was not the generator itself in $43 \%$ of cases.
About one in every three patients stopped pacing before the pacemaker was replaced.

Attempts should be made to improve follow-up procedures for paced patients.

Thanks are due to the suppliers of the pacemakers concerned and to the many physicians, surgeons, and technicians who completed and returned the very full questionary.

\section{REFERENCES}

Chardack, W. (1967). In Cardiac Pacing and Cardioversion, Sympostum of American College of Cardiology, p. 60. Philadelphia. Johansson, B. W. (1966). Acta med. scand., 180, Suppl. No. 451. Johansson, B. W. (1966). Acta med. scand., 180, Suppl. No. 451. Parsonet, V., Gilbert, L., and Zucker, I. R. (1966). Ann. thorac. Surs. 2., 561 .

Sowton, E. (1967). Mod. Conc. cardiovasc. Dis., 36, 31.

\title{
Long-term Transvenous Cardiac Pacing with Chardack-Greatbatch (Medtronic) Pacemaker
}

\author{
W. FORBES,* M.B., CH.B., PH.D., F.R.C.S.ED.; G. D. GREEN, $†$ B.SC.(C.ENG.), M.I.E.E., A.INST.P. \\ G. B. SHAW $\ddagger$ M.B., CH.B., B.SC., F.R.C.P., F.R.C.P.GLASG. ; $\mathbb{W}$. BAIN,§ M.D., F.R.C.S.BD.
}

Brit. med. J., 1968, 2, 13-16

It is now accepted that the rational treatment for chronic atriorentricular block is continuous pacing of the heart with an implanted pacemaker. The logic of this was first put into practice by Elmqvist and Senning (1960) and by Zoll and Linenthal (1960), followed later that same year by Chardack et al. (1960). Since 1962 implantable pacemakers have been used in Glasgow (Glass et al., 1963a, 1963b ; Bain et al., 1967) and a variety of types tried. The earlier epicardial pacing systems were attended by a high rate of failure, necessitating in many cases two or more changes of pacemaker. In the last few years, however, advances in technology and increasing experience in the use of pacemakers have combined to produce more reliable generators and catheter electrode systems. Furthermore, the demonstration of the simplicity and effectiveness of the transvenous method of permanent cardiac pacing (Parsonnet et al., 1962 ; Siddons and Davies, 1963 ; Lagergren and Johansson, 1963), requiring no thoracotomy, made the transvenous method immediately attractive.

In 1964 we in Glasgow became impressed with the superiority of the Medtronic generator and bipolar electrode catheter for endocardial pacing, and since then have used this exclusively as the unit of choice for fixed-rate pacing.

Between October 1964 and 17 November 196753 Medtronic fixed-rate endocardial pacemakers have been implanted in 44 patients in the Glasgow area. One pacemaker has been inserted in each of 37 patients, two pacemakers in five patients, and three in two further patients. These pacemakers have been implanted for periods of time varying from 1 to 33 months. The ages of the patients ( 24 men and 20 women) at the time of first implantation ranged from 32 to 84 years. Over $70 \%$ were 60 years of age or more.

Presenting Symptoms.-(1) Stokes-Adams attacks occurred in 29 patients. (2) Fatigue was the only symptom in five

- Lecturer in Cardiovascular Surgery, Royal Infirmary, Glasgow C.4. † Assistant Regional Physicist, Regional Physics Department, Western

¥ Consultant Cardiologist, Southern General Hospital, Glasgow S.W.1. S Senior Lecturer in Cardiovascular Surgery, Royal Infirmary, Glasgow
C.4. patients; it was combined with dizziness in three others and with angina in one more patient. (3) Dizziness was the sole complaint in three cases. (4) Intermittent claudication was the only symptom in one man. (5) Dyspnoea associated with congestive cardiac failure was the chief symptom in two patients, but occurred in combination with Stokes-Adams attacks in 12 others.

\section{Clinical Findings (Table I)}

Persistent complete heart block was found in 32 pattents and intermittent complete heart block in the remaining 12. Superimposed on these atrioventricular dissociations nine patients had developed dangerous tachyrhythmias, either before temporary pacing or during insertion of the temporary catheter electrode. Ventricular tachycardia occurred in five of these cases and bursts of multiple ventricular extrasystoles in four others. Of these nine patients three developed ventricular fibrillation and one asystole. In addition to these nine patients another man had developed ventricular fibrillation during implantation of a previous epicardial pacemaker unit. These five patients were successfully resuscitated and were alive and well at the time of writing.

There was a history of myocardial infarction in eight patients and of generalized ischaemic heart disease in 13. In the remaining 23 no obvious cause was found for the heart block. A basal blood-pressure recording of $160 / 95 \mathrm{~mm}$. Hg

TABLE I.-Clinical Background of 44 Patients Treated with a Medtronic Implanted Pacemaker

\begin{tabular}{|c|c|c|c|}
\hline Condition & & Number & Percentage \\
\hline 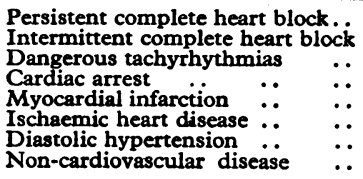 & $\begin{array}{ll}\because & \because \\
\because & \because \\
\because & \cdots \\
\because & \cdots \\
\therefore & \cdots\end{array}$ & $\left.\begin{array}{r}32 \\
12 \\
10 \\
5 \\
8 \\
13 \\
9 \\
15\end{array}\right\} 2$ & $\begin{array}{l}72 \cdot 7 \\
27 \cdot 3 \\
22 \cdot 7 \\
11 \cdot 4 \\
18 \cdot 2 \\
29 \cdot 5 \\
20 \cdot 4 \\
34 \cdot 1\end{array}$ \\
\hline
\end{tabular}

